\title{
The Study of Electronic City and Electronic Citizen
}

\author{
Seyed Valiollah Mirhosseini ${ }^{1}$, Seyed Mohsen Mirhosseini ${ }^{2}$, Ommekolsoum Haddadi $^{3}$ \\ ${ }^{1}$ Department of Business Administration, Payame Noor University, Iran \\ ${ }^{2}$ Faculty of Human Science, Yazd University, Yazd, Iran \\ ${ }^{3}$ Payam e Nour University, Yazd, Iran
}

Copyright (C) 2015 Horizon Research Publishing All rights reserved.

\begin{abstract}
Electronic city is a city where its citizens' affairs; including governmental services and private sector organizations are online and are doing their duties as boarding, seven days a week, high quality and safety By taking advantage of information and communication technology tools (ICT) and its usages. Overall the Smart City project means that all required services must provide to the citizens through the information networks; Thus there is no need for the citizens to travel to access governmental services and private institutions, in other words, Digital Offices are replaced by physical offices and Units and agencies such as municipalities, public transport and water display their services to their customers virtually. Nowadays, with the development of electronic technology and communication and emphasizes the problem of creating smart cities has created many jobs that meet their needs. Nowadays, development of electronic technology and communication and emphasizes on the creating of smart cities have been created many jobs that meet their needs. Developed countries have provided the possibility to governments to Transparent their activities, Especially in areas where have direct contact with the people, not only to reduce the violations resulting from the wrong administrative structure, but also to facilitate urban life and the availability of essential services to people. This paper aims at defining electronic city and its goals in the developing world. The aim of this paper is to identify electronic city and its principals in relation to each other.
\end{abstract}

Keywords Electronic City, E- Government, Electronic citizen, Electronic municipality, E-learning; E-commerce

\section{Introduction}

"The people of the earth currently have left behind three major waves of change", wrote Alvin Toffler in his book "The Third Wave". "The first wave, that its beginning is unknown to anyone, is agricultural revolution. The second wave that followed the invention of the stream engine in 1764 is industrial revolution. Finally, the third wave that began in 1964 and man was achieved to build computer, is IT revolution. Each of these waves creates its own intellectual and cultural developments [1].

Third Wave is called wisdom wave because everything is defined and for each definition a code is considered. In other words, people are not recognized by their ancestral name, rather each person has an independent identity that is summarized in the form of figures. At the third wave, assigned to specific individuals, races and nationality is not a benchmark for excellence and recognition rather computers classify and divide the people according on the basis of numbers. The Electronics City that is one of the achievements of the Third Wave is not an exception. Notable element is rapid development of electronic life elements and transformation of economic, social and political dimensions. Therefore, coexistence and consensus that is essential to communicate as the basic initial comprehensive information display at electronic city [2].

New ways of interaction, especially internet has provided different forms of virtual environments, this lead to a great evolution in any aspect of organizations and human beings life. This technology changed people, organization and government's performance and attitude and created new industries, Jobs, creativities for doing things. The advent of some phenomenon like smart cards, electronic banking, electronic education, electronic health, electronic business, electronic government and the like that redeveloped recently are the result of IT development in any aspect. This lead to the formation of electronic city in which great amount of activation \& services in the city were performed electronically, the paper is going to investigate and study the importance role of electronic city and electronic citizen in order to contribute to the body of knowledge and give a real perspective about electronic market. The purpose of the paper is to investigate the importance and Benefits of the electronic city and electronic citizen in the today's world.

\section{Definition of Electronic city and Electronic Citizen}

1) Electronic city 
Electronic City is a city where citizens' affairs including Governmental services and private sector organizations are done online, Boarding, Seven days a week, high quality and high safety and using ICT tools and its applications [3]. In electronic cities all requirements of citizens are provided through computer networks. Therefore, electronic city is somehow a relative term; the more services provided by computers, the more the meaning of electronic city will be clarified. [3]

\section{2) E-Citizen}

e-citizen is who have the ability to work with computers and could be able to use the internet for implementing faster and more effective of everyday life, such as communicating with others, buying and selling banking transactions, employment, travel, leisure, entertainment, and so on.

An electronic citizen can be defined by electronic government. In fact, it is the union of ation and government that are inseparable. (Bahri \& Sadeghpour. etal, 1388:P. 9(

This concept expresses characteristics of a citizen in information community. The citizens of information community is the one who is able to use hardware and software technology In many countries, electronic government is based on electronic state according to the viewpoints of electronic municipality. Electronic government is based on electronic city. [4]

3) The importance and necessity of development and expansion of electronic city

Resolving the problem of traffic, air pollution and saving time will be realized with the electronic city. Lack of fitness of Capacity of city with its population, millions of daily travels that perhaps thousands of them are unnecessary, the heavy traffic caused by the daily commute of millions of vehicles, wasting time of Citizens of in traffic for hours and air pollution that becomes more critical every day, all mentioned factors these days faced big cities with the problems and disorders to the big cities. In such circumstances, Experts and scholars of urban issues believe Fulfillment of the terms (Electronic City) is one of the fundamental ways to go out of this chaos condition [5].

Three indexes of implementing electronic city are: Political, technical and organizational. Political indexes pay attention to macro policy making acts, strategy making, citizenship charters, the administration and bureaucratic setting of the city, along with the development of society's information is requisite. Regarding technical indexes it is necessary that municipalities focus on establishing electronic ties between organizations, facilitating internet connections and providing cohesive ties between the related organizations. In organizational indexes, if we assume the city an huge organization, the citizens will be like customers and they should be at the centre of attention. Electronic city provides some qualifications that will facilitate meeting citizens' needs. [6]

4) The goal of development and expansion of electronic city

The main objective of electronic city is providing high quality services at affordable prices to everyone. Some of the objectives of the electronic city are: Creation of the perfect environment to improve living standards, Business, Providing online access environment to data and urban utilities (instead of keeping citizens in line), Improving of the quantity and quality of services of city agencies, GDP growth and increasing of the incomes and Coordination of all city departments, as well as cost savings.

Therefore, we can classify the advantages of electronic city as the following:

a. Providing high quality internet services for citizens with high speed.(creating an appropriate infrastructure in order to connect to Internet and global network )

b. Improving the quality of life with facilitating urban activities (activities pertaining to city life) and economic status of the city which is the result of life improvement in cities and public knowledge of urban qualities and processes.

c. Defining urban communication by IT and electronising them which lead to one stage service provision. Consequently, there will be no need to frequent \& subsequent reference to offices and different organizations.

d. Improving the relationship between organizations and different organs of the city electronically. Facilitating communication via internet and established infrastructure made by municipalities.

e. Connection availability between citizens and business men, municipalities, those responsible in the government in order to solve problems in cities. Therefore, the problems of the cities will be solved rapidly. [7]

\section{5) The basic features of the electronic city}

Goal of the electronic city is: providing better services, with lower costs and higher effectiveness but it could not introduce certain standard for other features, because each city can build its electronic city system regarding to the needs of its society.

6) Electronic preparations: the necessity of entering the electronic city

Before running of the detailed and complex electronic city program, it is important to be aware of the level of preparedness of the city to carry out such projects. E-readiness presents the degree of city preparation to participate in transferring and developing of information and communication technologies (ICT) in order to achieve the global information society.

There are five main axes usually are considered for e detection readiness and evaluation of electronic city:

Infrastructure

Human Recourses

Administration and Urban governance

Rules and Regulations

Budget and Finance [8].

7) The requirements of the electronic city 
Three components are required to create electronic city: E-Government

E-commerce

E-Learning

\section{1.) E-Government}

E-government is transforming and Statecraft processes through making it more accessible, more efficient and more accountable and also providing information and services to citizens and other governmental agencies using information and communication technology (ICT) [9]. Electronic government includes four basic aspects of: government and people, government and private section, government and employees, government and other sections. Electronic government is a method for states to use new Technology that provides facilities in order to have access to information, government services, improving their qualities and providing opportunities in order to take part in some events. In fact there is no definite way of describing Electronic government and this may be because of dynamic and versatile technology. The purpose of IT and communication is improving efficiency, impression, clarity of information and exchanging money and information inter and intra states and organizations, government and citizens, government and private section of electronic government. [9]

\section{7-1-1) Benefits of e-government}

The benefits of the e-government are as following items:

1- increasing Citizen empowerment through access to information and more effective management of public affairs.

2- Improving communication between government agencies with trade, industry and other governmental agencies.

3- Increasing the accuracy and transparency in government affairs.

4- Growth of Government revenues and reducing its costs.

5- Improving of the efficiency of the economic systems and creating transparency for attracting foreign investments and support in developing countries.

6- Creating a better sense in social participation and amending the decision-makings and implementation of development planning

The overall objectives and priorities for lunch

e-government are:

1. Increase the effectiveness and efficiency of internal operations of the government sectors

2. Reducing the costs of government

3. Raising the level of customer satisfaction with the services provided to them through

4. Support economic development programs [10].

\section{7-1-2) The Fields of application of the E-Government}

E-government has many different applications that can be classified into the following four groups:

1. relationship of government with the citizens
Includes from informing the public to paying bills such as water bills, electricity bills, telephone bills and traffic penalties through the internet network

2. Relationship of the government with trade and industry

Such as licensing of the certificates and buying and selling of goods and services via the internet [11]

\section{Relationship of Government and employees.}

Aim is providing information to the public employees using domestic governmental networks, such as personnel information, retirement benefits of personnel and the latest news related to the activities and the demands of the other employees.[12]

\section{4. relationship of government with government}

Relationship of governmental organization through internal networks.

\section{7-2- E-commerce}

In today's world we are facing the huge volumes of electronic transactions and e-commerce is an integral part of electronic world. Today big Stores easily sell their products via the Internet and companies organize their massive exchanges on the Internet. Today, Branches of e-commerce are so widespread that companies are working in particular context internationally. Investment, Electronic marketing, electronic payments, online stores, big auction markets, all include only a bit of the vast e-commerce world. [13]

Overall, today's world is confronting dramatic expansion of e-commerce and replacement of electronic money instead of paper money. Among the advantages of e-commerce and digital money are saving time, Fast trade and reducing the printing costs and so on [14].

\section{7-2-1) Benefits of E-commerce}

Scope of benefits of $\mathrm{E}$ - trade grows day to day and a greater share of world trade is done by e-commerce every year. The main advantages of e-commerce can be outlined as follows:

1. There is a lot easier in buying and selling of goods and providing after sales services

2. The customer will enjoy top choice power and can take a tour to many virtual stores and select their desired products.

3. Saving in various costs of business activities such as document preparation fees and sales factors between 21 to 70 percent.

4. Geographical distances are removed [15].

\section{7-3) E-Learning}

Education is the most important lever to increase the effectiveness of economic success and growth of the labor trained force. In the e-Learning, companies, intellectuals, educators and teachers can work together. Whatever the technologist and teachers have more time and more worked together, the talents of the students will be more flourished. 
Regardless of the virtual learning infrastructure and its objectives, cannot be hoped its Implementation and effectiveness. It is necessary to recognize the infrastructures before making any decision, and then implement it regarding to virtual learning education goals [16].

\section{7-3-1) Benefits of E-Learning}

Benefits of e-learning are improved due to the increasing of its capability, but in general, most cases can be cited as follow:

1- Student mobility during training and promoting research, In fact, the integration of education and research at each other during the learning process

2- Removal the problem of Professor pivotal

3- Bridging the gap and distance between locations and availability of data of all science disciplines in minimum possible time and in any place

4- Lack of appropriate educational materials to a particular group and access to public both unemployed and employed persons...

5- Saving in time and costs

6- Increasing of Skilled manpower and Consistent with technology [17].

\section{8) Steps of Creation of the electronic city}

Electronic City Development can be implemented based on the implemented models in the world according to the following steps:

The first stage:

1- Preparation of Law on Electronic City

2- Presenting of Internet facilities and Designing Web Sites for governmental agencies and private sector

3- Creating appropriate structures in the Ministry of Interior and Management and Planning Organization

4- Increasing public awareness of citizens and government employees to the information technology capabilities

5- Training of specialists in IT

6- Creating the required network between organizations [18].

The Second stage:

1- Supplying Electronic Services to Citizens

2- Production, distribution and use of digital information in governmental and private units of electronic city

3- Developing specialized training for government employees and special training for citizens

4- Development of Functional Software systems in the ECity units [19].

The Third stage:

1- Creating information interaction between the public and private sectors

2- Creating information interaction between citizens and governmental agencies and the private sector in the electronic city

3- Development of Interactive learning and new business
4- Promote of Necessary Standards for handling the electronic city [20].

The Fourth stage:

1- Creating integrated public systems (e-commerce, e-banking, e-learning, the tax system, etc.) in the offices, organizations, companies, trade unions and other electronic sectors

2- Doing Special transactions electronically

3- Creating virtual and international organizations in business, education, health and...

4- Information interaction at the national level with the private sector of governmental organizations

5- Exchanging information with the global information society as citizens of the Third Millennium

6- Regularly review and update of policies and programs of electronic city

7- Continuous improvement of electronic systems [21].

\section{9) Outlook of Electronic City}

1- Providing Satisfactory service to citizens and tourists at any time and any place

2- Creating dynamic and competitiveness economic environment

3- Reducing within the city trips with the development of IT applications

4- Transparency of business processes

5- Providing all on-line services required by citizens

6- Creating a pilot city to live, work and fun [22].

\section{0) Influences of Electronic City}

If we accept that the process of people living in this century is towards becoming more electronic and believe that electronic life is becoming a reality, then we'll find that no aspect of the human life will not go away from the impact of this Phenomenon, It's enough to Look around to see how Electronic life is surrounding all areas of human life, one after another, and had its Negative and destructive effects with its positive and negative features. Although all the human societies at various levels enjoy the benefits and facilities of the electronic life, or at least talk about it but few people have considered damages caused by the spread of this Complicated and complex phenomenon that its aspects are unknown and amazing [23].

\section{1) The benefits of electronic city}

Since in the electronic City most of the people's daily tasks are done electronically by using IT, so it will follow many benefits, which some of them include:

- Providing high quality and high speed Internet services to citizens

- $\quad$ Providing various training Channels and lifelong learning environment

- Improvement Quality of people's life

- $\quad$ Provide one-stop service to citizens

- $\quad$ strengthen businesses competitiveness of city and creating more business opportunities by e-trading 
- Better communication of various civic organizations

- 24-hour access to city services

- Increasing public participation in city affairs

- Reducing the traffic use of the Internet, according to the Urban Citizens

- Reduction of city traffic due to the use of the Internet in Urban activities of Citizens

- Reducing air pollution by reducing city traffic

- Aligning of the Investments with the needs of citizens

- Accelerating the Eliminating of problems in city and direct communication of municipal authorities with the citizens

- $\quad$ Saving time and energy

- Avoiding more investing on the old methods of city controlling

- Creating needed infrastructure for future developments of city

- Reducing Corruption

- Increasing regulation in the city activities using a comprehensive information system

- Increasing level of public awareness

- Creating fixed urban income with the creation of a stable and comprehensive circulation of money system

- $\quad$ spreading of Culture and beliefs

- Management and Monitoring of Urban Unit [24].

12) Disadvantages of electronic city

Some of the disadvantages of electronic city are as follow:

\section{2-1) Electronic decoupage}

The first Complication is decoupage of the man who has threatened the physical body of users, resulting working closely with the electronic tools and is brings of modern life and is associated with the electronic. For instance, muscle pain, wrist pain, back bending and localized pain in the majority of computer and Internet users are samples of the electronic decoupage that are increasing day by day, Also working too much on computers leads to vision problems such as redness, irritation and Runny eyes and finally leads to Loss of vision, fatigue and headache. Continuing to work with computers also has other risks that are unknown dimensions to us, such as the risk of Releasing electrostatic waves, spreading radiation and light waves, risk of spreading poisonous gases caused by warming Computer Parts and...

\section{2-2) Electrical isolation}

Individualism is another injury of electronic life that contains within it a fence for man, who cannot simply get away from it. Electronic Life will increase satiety effect in humans; instead it will reduce hardly natural interaction in social relationships.

singleness is nature of using electronic devices Including computers that leads to virtual or private world, Destruction people of community and detrimental and deep that its dimensions cannot be clearly explained. Attractiveness of virtual world is too much so that after a while, Electronic Life Members will not tolerate communication with others, and like a drug addict who has always drawn towards his companion and drugs soon will come to his individuality and electronic instruments. In this case, only the virtual communication through waves will pervade on individual communication of society and gradually will make defective human nature. For example, it can be noted the relations between parents and children who are among the first victims of Electronic Life. In the electronic world the Family will severely damage and its members will exclude from many natural benefits resulting its logical engagement, that of course, the scope of it is beyond the relations between parents and children and even will target marital relationships.

\section{2-3) bombarding of electronic information}

With the advent of the Internet that in a sense, gives its users everything in electronic format, and integrated multi-media, will fatigue its users very slow and creeping. Millions of websites and billions of blogs and trillions of web pages on various topics, at once, are ambushing the internet users and dozens of right and wrong pages invade the users. The human being cannot get rid of bombardment of electronic information although he has the high power of Processing and analyzing, because in one moment, thousands of hints are calling him, so, in this way, Human beings will become the ones that will be confronted with a lot of information on the one hand, and on the other hand, he will not have permission and the possibility of deep thought and Naturally processing that its natural consequence will be electronic stress and frustration.

\section{2-4) Electronic Violence}

Violent instinct is one of the human instincts which like other instincts is institutionalized in the human structure, if flames up, make the man into an unpredictable and out of thinking. Aside from Promotion of Violence in the Media and Satellite TVs, Now tens of thousands of sites on the Internet are promoting different forms of violence to achieve to their financial goals that annually is billions of dollars.

\section{2-5) Electronic Pornography}

Accessing to pornography images and videos, especially for children and youth in the information superhighway or the Internet, is a very serious and disturbing issue that had challenged many Families and many cultural and educated Strata of societies. This counter-cultural and electronic anti-moral cases at the internet which consists of tens of millions of electronic pages, has targeted core of Families especially Children and Young People.

\section{2-6) Electronic Addictions}

Researches and statistics show that there are addictive behavior patterns among frequent users of the Internet and their number is increasing constantly. Harming to children is the most disturbing aspect of Internet addiction, which engulfs them with its different appeals. So, children and youth are drawn into the group games and even its banal 
sections. Internet addiction should spoil many hours of the night and day of such people and will lead them to electronics hooliganism and aimless surface.

Inevitably, in future, the human society will experience digital homes. This phenomenon cannot be removed with physical force which only will lead to clearing up problem statement. Fundamental solution is recognizing, analyzing and Pathology of problems by scholars and professionals.

\section{Conclusions}

As technology improves, for many people, the house is as a Appropriate place to do their activities that were previously only possible through the Workplace. In addition, the development of mobile phones, handheld computers and other communication tools has changed the dynamic scheduling of tasks and activities in travel or outside of the living place and workplace. Information technology has also led to development issues such as flexible working hours and tele-working. Freight is also influenced by developments in information technology and has been transformed in many ways. So, access can no longer be measured only by factors such as travel time, distance or cost. Any person who insures his purchases from home via the internet, and is informed the Facilities of transportation systems before traveling, will caused changing to travelling patterns. Regularly a significant proportion of people in different societies, somehow, will use communication tools to remove unwanted trips or changing the time or redirecting trips to avoid hours and directions of traffic jams. Previous exposure indicates that people are presenting smart ways to avoid congestion and paying additional costs in traveling behavior.

Objectives and benefits of IT, Especially in the form of electronic city, Such as lower cost of services, changing working hours, Availability for all, And its other capabilities if be done actually, can easily satisfy both the users of this system and Accountable officials in the civil service scope.

In most major cities a large percentage of the problem of air pollution is caused by traffic, but the important thing is that necessarily solving the traffic problem will not solve the problem of air pollution. So it is important that we should seek the solution of traffic by solving simultaneously the problems of "Traffic" and "pollution", and the best way to solve these two problems, is using new electronic city technologies.

\section{REFERENCES}

[1] Taghavi, Bahram, limitless Antwerp of City, Anformatic journal, 2011, No.63.

[2] Inhibition of traffic in smart city, Hamshahri newspaper, October 22, 2007.

[3] Jalali, Aliakbar, advantages of electronic city, Donyaye Eghtesad newspaper, May 01, 2003.
[4] Mahaki Aliasghar, Electronic Municipality, 2008. Takfa Magazine, 5th year, Number 2, pp. 77-78.

[5] Shekarkhah, Younes, Smart City, Sanat e Chap journal, 2010, No.183.

[6] picture of one day Life in the Electronic city, Abrar e Eqtesadi newspaper, 16/01/2006.

[7] Safari Saeed, Kanaani Ahmad, Baghlou Ali, 2008. Electronic Municipality Base of the Electronic City, First International Conference on Electronic City, International Congress saloon, Milad Tower, Isfand 1th and2nd, Tehran. pp. 5-15.

[8] Montazer Gholamali, Sadattahami Sara, 2010. Codification of Designing Ways to Create a Digital City in Tehran in the Perspective of 1404, Second International Conference on Electronic City, Orddibehesht, 22nd to 23rd, Tehran, pp. 2 - 3.

[9] Jalali, Aliakbar, advantages of electronic city, Donyaye Eghtesad newspaper, May 01, 2003.

[10] Shabani, Ahmad (2005), Principles of development and application of ICT in the education system, Oloum e Ettela Rasani journal, 2008,Vol.89, No.34.

[11] advantages of electronic city, Khabar journal, May 11, 2003.

[12] Atashk, Mohammad (2008), Theoretical and practical Basics of e-learning, Pajouhesh va Barnamehrizi Dar Amouzeh journal, Vol.13, No.1.

[13] Jalali, Aliakbar (2004), electronic city, Elm o Sanat e Iran pub.

[14] Ayati, Mohsen, Atarat, Mohammad, Mehrmohammadi, Mahmoud, (2008), Curriculum development model based on information and communication technologies in teacher education center, Motaleaat e Darsi journal, No.5.

[15] Shabaninejad, Reza, Sadeghi, Reza (2008), ICT in Education, Peyvand e Mehr pub.

[16] Jalali, Aliakbar (2007), electronic city, Tehran: Elm o Sanat e Iran pub.

[17] Bousalvo (2006), Cyber imperialism \& global relations in the new era of electronics, Alavi, Parveez, Tehran: Sanieh pub.

[18] Seet, Elahe, Vision of smart city, Shargh newspaper, October 04, 2004.

[19] Dehnaei, Morteza, Creating value from data, Sanat e Haml o Naghl journal, 2009,No. 211.

[20] Safavi, Mohammad, Electronic City and its position in the world economy, Abrar e Eghtesadi, October 31, 2001.

[21] Farajlou, Touran, from city state to electronic city, Jahan e Eghtesad newspaper, September 28, 2004.

[22] Jalali, Aliakbar (2005), Curriculum in the age of information and communication technology, Tehran: Anjoman e Barnamehrizi e Darsi e Iran.

[23] Hantington, Samouel, The third wave of democracy in the twentieth century, Shoma, Ahmad, 1994, Tehran: Rozaneh pub.

[24] Jalali, Aliakbar, electronic city of Mashhad, Hamshahri newspaper, May 13, 2003.

[25] Kalantari, Khaleel, Planning and Regional Development (Theory and Techniques), 2001, Tehran: Khoshbeen \& Anvar e Danesh pub. 